\title{
Analisa Investment Casting Perannya untuk Reparasi Towing Beam Kapal Tunda dengan Metode Elemen Hingga
}

\author{
Samuel Febriary Khristyson, Sulaiman, Riend Prahasti* \\ Prodi D3 Teknologi Perancangan Konstruksi Perkapalan, Departemen Teknologi Industri, \\ Sekolah Vokasi, Universitas Diponegoro \\ Jl. Prof Sudarto, SH, Tembalang, Semarang, Jawa Tengah, Indonesia \\ *E-mail: riendprahasti08@gmail.com
}

Diterima: 20-01-2020; Direvisi: 23-08-2020; Dipublikasi: 01-09-2020

\begin{abstract}
Abstrak
Negara kepulauan dapat memanfaatkan laut sebagai media transportasi dan termasuk dalam sarana transportasi dengan kriteria ekonomis dan terjangkau. Sehingga armada pelabuhan di kota-kota pesisir sangat membantu dalam proses loading dan shifting kapal-kapal dengan ukuran besar untuk berlabuh ke sebuah dermaga. Bagian dari kapal tunda yang memiliki peran untuk mengatur dan menarik tali tambang adalah bagian konstruksi towing beam. Konstruksi ini berbahan plat dapat mengalami deformasi akibat beban statis ketika menerima tegangan dari tali tambat yang di hubungkan kepada kapal tongkang. Salah satu upaya untuk memberikan pembaharuan adalah dengan bahan cor, dengan modern investment casting. Sebelum dilakukan pembuatan model castingnya maka perlu dilakukan analisa pada bagian towing beam yang menjadi bagian kekuatan agar menciptakan desain yang optimal dengan metode elemen hingga. Tujuan penelitian ini untuk membandingkan penerapan investment casting pada reparasi towing beam kapal tunda dapat menjadi peluang usaha baru bagi industri manufaktur serta faktor-faktor yang perlu diperhatikan pada saat proses investment casting. Adapun hal-hal yang perlu diperhatikan dalam produksi dengan sistem Investment Casting: konsep desain dari model lilin, penggunaan material, akurasi dimensi, jenis densitas materialnya, lapisan ketebalan dari cetakan, serta model support untuk menahan selama proses pengecoran. Dari hasil analisa tegangan maksimum untuk membuat desain yang optimal dari casting pada daerah pengamatan luar adalah $180,12 \mathrm{~N} / \mathrm{mm}^{2}$ dan pada daerah pengamatan dalam adalah 143,34 $\mathrm{N} / \mathrm{mm}^{2}$.Sedangkan untuk penerapan investment casting pada produksi towing beam kapal tunda dapat menjadi peluang usaha baru bagi industri manufaktur karena dapat mempersingkat waktu dengan man power yang sama sebesar 52\% atau selisih estimasi waktu 15 jam setara dengan 2,5 hari kerja. dan memperingan biaya fabrikasi bagi industri galangan kapal sehingga mereduksi biaya reparasi $41 \%$ yaitu mengurangi biaya fabrikasi dan quality repair cost
\end{abstract}

Kata kunci: Investmen Casting; Kapal Tunda; Towing Beam;

\begin{abstract}
An island nation can utilize the sea as a transportation medium and is included in the means of transportation with economic and affordable criteria. So that the port fleet in coastal cities is very helpful in the process of loading and shifting ships with large sizes to port at port. The part of the tugboat which has the role to arrange and pull the mooring rope is the construction part of the towing beam. This construction made of plate can be deformed due to static load when receiving tension from the mooring rope which is connected to the barge. One of the efforts to provide renewal is with casting materials, with modern investment casting. Before making the casting model, it is necessary to analyze the towing beam that becomes part of the strength in order to create an optimal design with the (FEM) finite element method. The purpose of this study is to compare the application of investment casting on the repair of towing beam tugboats can be a new business opportunity for manufacturing industry as well as factors that need to be considered during the investment casting process. As for things to note in production with Investment Casting system: design concept of wax model, material use, dimension accuracy, material density type, thickness layer of mold, and support model to withstand during casting process. From the results of the maximum voltage analysis to make the optimal design of casting on the outer observation area is $180.12 \mathrm{~N} / \mathrm{mm}^{2}$ and in the deep observation area is $143.34 \mathrm{~N} / \mathrm{mm}^{2}$. As for the application of investment casting on the production of towing beam tugs can be a new business opportunity for manufacturing industry because it can shorten the time with the same man power by $52 \%$ or the estimated time difference of 15 hours is equivalent to 2.5 working days and reduce fabrication costs for the shipyard industry so as to reduce repair costs by $41 \%$ that is reduce fabrication costs and quality repair costs.
\end{abstract}

Keywords: Investment Casting; Towing Beam; Tugs 


\section{Pendahuluan}

Negara kepulauan dapat memanfaatkan laut sebagai media transportasi dan termasuk dalam sarana transportasi dengan kriteria ekonomis dan terjangkau. Salah satunya adalah negara Indonesia dimana memiliki luasan lautan hampir 76 persen dari wilayahnya [1]. Sehingga armada pelabuhan di kota-kota pesisir sangat membantu dalam proses loading dan shifting kapal-kapal dengan ukuran besar untuk berlabuh kesebuah dermaga. Studi mengenai perancangan sistem propulsi kapal kontainer 100 teus sebelumnya, menerangkan bahwa transportasi laut dapat meningkatkan perekonomian dan menjadi sarana memperkuat hubungan antar kebutuhan [2]. Banyak alur pelayaran di sungai yang menggunakan kapal dengan aksesibilitas yang cukup mudah dan tenaga yang kuat sehingga dapat digunakan untuk membawa atau menarik muatan dengan kapasitas yang cukup besar. Sebagai contoh adalah kapal tunda atau yang sering disebut dengan tugboat. Studi terdahulu menerangkan bahwa kapal tipe ini memikili daya power yang cukup besar untuk menunda atau memandu kapal-kapal besar masuk kedalam perairan kecil antar pulau dalam dermaga pelabuhan atau perairan sungai [3]. Bagian dari kapal tunda yang memiliki peran untuk mengatur dan menarik tali tambat adalah bagian konstruksi towing beam, lihat pada Gambar 1. Konstruksi towing beam berbahan plat dapat mengalami deformasi akibat beban statis ketika menerima tegangan dari tali tambat yang di hubungkan kepada kapal tongkang. Senada dengan penelitian kekuatan poros kemudi [4], beban geserkan yang diterima oleh benda berbentuk tabung akan menerima tegangan geser terjauh dituangkan dalam Persamaan 1.

\section{$\frac{p}{c} x \tau \max$}

Dimana $\rho$ adalah jarak jari-jari lingkaran $(\mathrm{mm})$ dan c adalah kofisien gesek tegangan geser terhadap ujung benda, sedangkan $\tau$ max adalah nilai tegangan maksimum yang terjadi $\left(\mathrm{N} / \mathrm{mm}^{2}\right)$. Maka sebagai upaya dalam pengoptimalan desain dan jangka waktu penggunaan yang lama,perlu adanya studi mengenai proses dan bahan pembuatan towing beam yang tepat dan cocok untuk pengaplikasian di industri pembuatan kapal tunda.

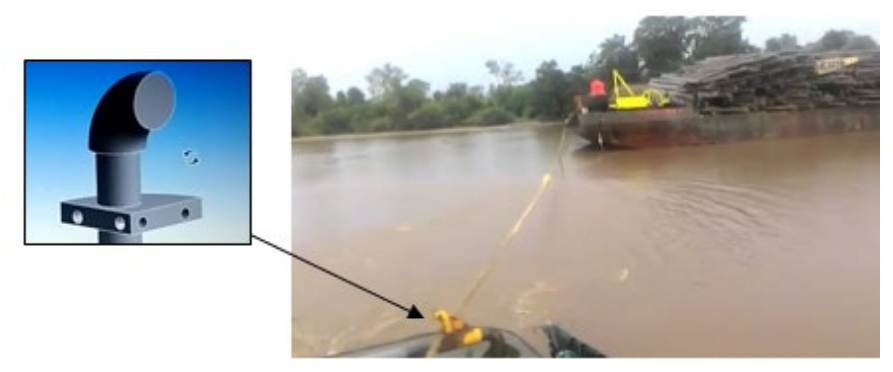

Gambar 1. Representasi Towing Beam Kapal Tunda

Salah satu metode untuk pebuatan produk dengan bahan cor atau casting dalah dengan investment casting, lihat Gambar 2. Pengertian dari metode investment casting sendiri merupakan suatu teknologi pengecoran dengan kualitas produk yang baik seperti kepresisian yang cukup tinggi dan dapat membuat produk dengan tingkat ketelitian yang cukup tinggi. Seperti contoh produk yang mampu diterapkan dengan metode investment casting ini cakupannya cukup banyak diantaranya mulai dari industri bidang kesehatan, pertanian, tekstil, senjata, elektronik, otomotif, perkapalan, penerbangan, militer dan komponen listrik yang sangat dibutuhkan Indonesia [5]. Studi sebelumnya dilakukan aplikasi terhadap 5 jenis lilin berbeda untuk pengecoran investment casting ini dari kombinasi lilin dengan takaran tertentu, dilakukan proses pencetakan menggunakan cetakan berbahan mild steel. Menyatakan bahwa persentase linear shrinkage 
dan volumetric shrinkage pola lilin terendah masing-masing 0,98\% dan 2,53\% [6], hal ini menunjukan hampir sedikit selisih yang terjadi artinya kemungkinan kepresisian hasil produksi dari investment casting dapat diterapkan. Mendukung penelitian tersebut studi terdahulu juga menunjukan Bahan silicone rubber juga dapat digunakan sebagai bahan alternatif dalam membuat cetakan pola lilin dalam investment casting, sehingga ketergantungan penggunaan bahan metal sebagai bahan pembuat cetakan pola lilin dapat ditekan nilai biaya (cost)-nya serta waktu proses untuk pembuatannya [7].

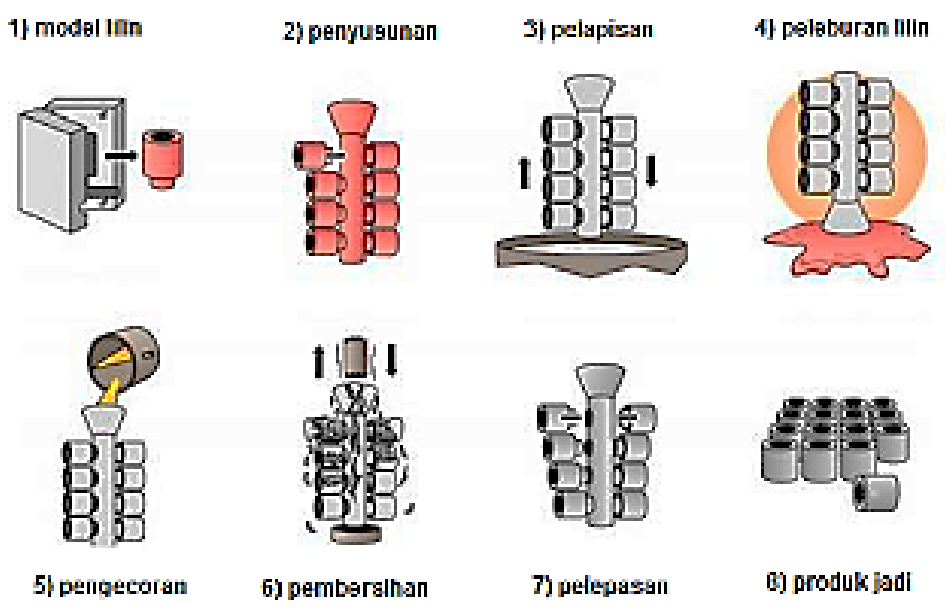

Gambar 2. Tahap pengecoran dengan Investment Casting [8]

Temperatur tuang ketika proses pengecoran dan sistem saluran dan cetakan inti dapat mempengaruhi hasil dari produk ini, hal ini dinyatakan juga dalam studi sebelumnya [8], diamana masteratau model awaldirancang sedemikian rupa guna memperlengkapi kelebihan dari pengecoran investment casting. Adapun rancangan yang dibuat dalam penelitian tersebut meliputi dari salurun turun (sprue) dan saluran masuk (gate) kemudian dilakukan perencanaan berdasarkan ketebalan rata-rata dari master yang ditentukan. Senada dengan hal tersebut cawan tuang (pouring cup) juga serta dapat menyesuaikandengan penampang atas sprue [9]. Kemampuan permeabilitas menurut studi [10] membuktikan adanya keuntungan ketika pembuatan cetakan dengan memperhatikan setiap detail sudut cetakan sehingga persebaran pengecoran menjadi merata. Bahan untuk membuat cetakan juga disarankan terbuat dari bahan yang berserat atau bertexture sehingga menambah ketahanan suhu ketika proses penuangan pengecoran. Suhu yang tertuang pada studi sebelumnya [11] menyatakan jika terdapat perbedaan nilai sekitar $40 \%$ tergantung dari ketebalan porsi cetakan dari investment casting.Berbeda dengan pendapat [12] menyatakan dalam investigasinya terhadap model yang dibuat dalam bentuk 3D menunjukan suatu benda sebelum dialakuakan pengecoran dengan teknik investment casting, ada baiknya dilakuakn modeling dengan mempehatikan setiap sudut masukan yang terbentuk pada lilin didalam cetakannya. Semakin rapi dan halusnya sudut yang terbentuk antara permukaan yang terbentuk memiliki sumbu diagonal sebagai garis isian yang membagi ruangan menjadi beberapa bagian sehingga memudahkan permabilitas raungan dan terisi cairan yang akan mengisinya [13]. Pembuatan model ini akan lebih mengoptimalkan sudut atau curva lengkung yang terbentuk pada suatu objek 3D menjadi struktur tengah dari cetakan investment casting, dapat dilihat pada Gambar 3. 


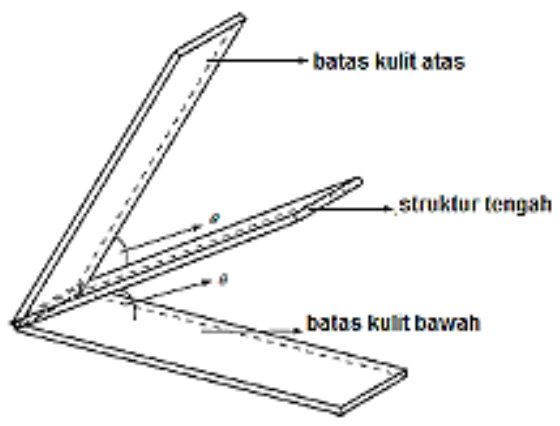

Gambar 3. Representasi contoh bagian sudut pada cetakan [12]

Berdasarkan investigasi perhitungan model dan perencanaan towing beam maka dapat ditentukan letak tegangan maksimum yang didapatkan sehingga diharapkan dapat membuat desain cetakan dengan permukaan yang halus serta menghasilkan produk yang optimal [14]. Reviewer sebelumnya menjelaskan penentuan hasil pengamatan sangat diperlukan untuk mendapatkan hasil cetakan yang optimal [15]. Penentuan pengamatan dilihat dari bagian yang dianalisa menerima tegangan terbesar (maksimum) ketika diopersikan. Towing beam yang terbuat dari hasil pengecoran akan menambah kekuatan konstruksinya sebagai pengatur tambatan pada kapal tunda. Fenomena yang telah ada, towing beam terbuat dari pipa yang di fabrikasi sedemikian rupa. Proses fabrikasi tersebut memerlukan waktu yang cukup lama dibandingkan dengan kecepatan dalam pemasangan saja. Namun demikian dari pemilihan material juga harus diperhatikan terkait dengan proses pemasangan konstruksi hubungannya dengan elektroda pengelasan. Hasil studi [16] menjelaskan bahwa terpadat perbedaan cukup signifikan antara proses investment castingpenggunaan bahan alumunium paduan seri 6061 dengan baja carbon, dimana nilai yang ditunjukan adalah nilai konseterasi porositas Al seri 6061 memiliki nilai 5,17\% sedangkan pada baja carbon memiliki nilai 8,44\%. Hal tersebut membuktikan perlunya perhatian khusus pada proses pengecoran dengan bahan baja carbon dari segi kekentalan yang berbeda dan permeabilitas ruangan dalam cetakan yang berbeda pula. Sebelum menentukan daerah yang akan dialakukan pengamatan terdapat beberapa pendekatan, bisa ditinjau dari segi kekuatan mekanika bahannya, atau ditinjau dari aplikasinya ketika dilapangan. Untuk mengetahui kekuatan mekanika bahannya maka harus mengetahui tegangan yang dapat diterima oleh benda tersebut [16], salah satunya dengan menggunkaan perhitungan tegangan von mises. Dalam perhitungan beban yang digunakan diasumsikan adalah beban dari kapal tongkang dengan ukuran standart panjang $100 \mathrm{~m}$ sebagai batas minimum dari perencanaan, karena ukuran kapal tongkang dibawah 100 m dianggap sudah melebihi kekuatan batas minumnya. Tegangan von Misses merupakan penjumlahan total antara tegangan hasil perhitungan yaitu terdiri dari tegangan utama dan tegangan geser sehingga hasilnya lebih komprehensif jika dihadapkan dengan tegangan yang lain, tegangan ini digunakan sebagai parameter untuk mengevaluasi unjuk kerja dari sebuah desain produk [17]. Dalam hal ini towing beam yang akan dibuat desain cetakannya dalam proses investment casting. Jika merujuk pada Persamaan 2,

$$
\sigma_{e} \sqrt{\frac{1}{2}}\left[\left(\sigma_{1}-\sigma_{2}\right)^{2}+\left(\sigma_{2}-\sigma_{3}\right)^{2}+\left(\sigma_{3}-\sigma_{1}\right)^{2}\right]
$$

dimana $\boldsymbol{\sigma}_{\boldsymbol{e}}$ adalah tegangan von mises, $\boldsymbol{\sigma}_{\mathbf{1}}$ adalah tengangan sumbu x, $\boldsymbol{\sigma}_{\mathbf{2}}$ adalah tegangan sumbu y, dan $\boldsymbol{\sigma}_{3}$ tegangan pada sumbu $\mathrm{z}$, seluruh satuan dalam $\mathrm{N} / \mathrm{mm}^{2}$. Bahan yang digunakan dalam proses pengecoran direncanakan dengan menggunakan baja karbon,sehingga diharapkan akan mempermudah proses assembly antara konstruksi towing beam dengan komponen struktur kapal. Berdasarkan sifat kareristik dari bahan investment casting pada penelitian 
sebelumnya [18] menunjukan volume ruang dalam pengecoran menentukan kekuatan karakteristik bahan suatu produk nilai ini terdapat pada angka perbandingan $68 \%$ kekuatan aktualnya dan $32 \%$ untuk analisa metode elemen hingga-nya artinya setiap produk hasil investmen casting memiliki nilai safety factor yang cukup akurat.

Adapun batasan permasalahan dari penelitian ini adalah kapal yang digunakan tipe kapal tunda dengan pendekatan dan perbandingan panjang sesuai standart klas Biro Klasifikasi Indonesia. Untuk beban yang digunakan dalam operasional digunakan berat dwt kapal tongkang 100 m ketika muatan penuh dikarenakan pada kondisi ini disumsikan hipotesis sementara beban maskimum yang di terima dari konstruksi towing beam. Tujuan penelitian ini adalah untuk membandingkan penerapan investment casting pada reparasi towing beam kapal tunda dapat menjadi peluang usaha baru bagi industri manufaktur serta faktor-faktor yang perlu diperhatikan pada saat proses investment casting.

\section{Metodologi}

Adapun dari hasil analisa tegangan von mises dengan Metode Elemen Hingga didapatkan dari model yang telah direncanakan tegangan terbesarnya terhadap beban statis maka didapatkan pada daerah yang berwana terang ,lihat Gambar 4 .Sehingga didapatkan daerah pengamatan seperti yang ditunjukan oleh Gambar 5.

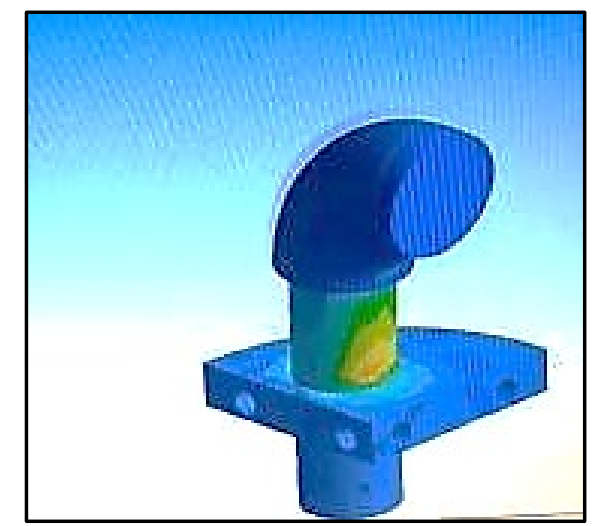

Gambar 4 . Distribusi tegangan von mises akibat Gaya tunggal pada towing beam

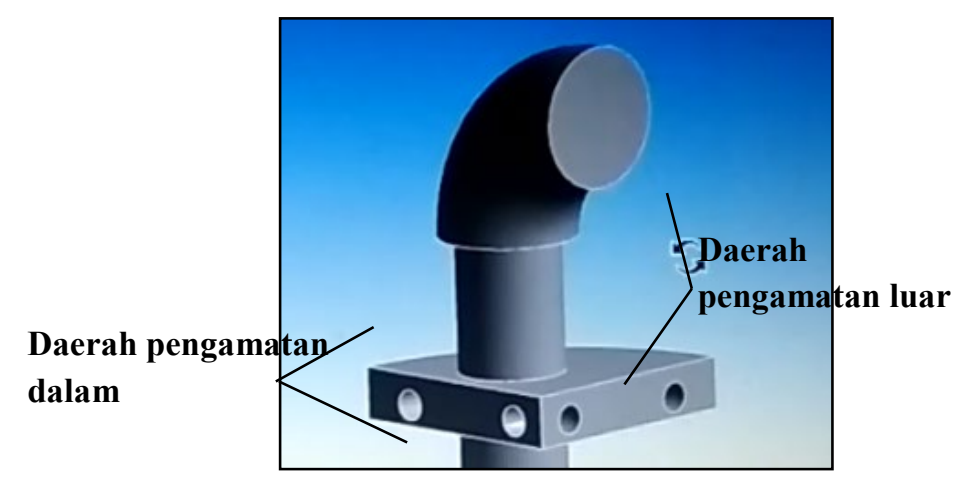

Gambar 5. Daerah pengamatan

Persiapan uji eksperimen untuk membandingkan proses reparasi towing beam dilakukan di salah satu industri galangan kapal di daerah Semarang. Dengan memperkerjakan man power yang sama yaitu 3 orang sebagai fitter, welder, helper untuk proses reparasi. 


\section{HASIL DAN PEMBAHASAN}

Hasil dari penelitian ini adalah perbandingan dan penerapan rencana pengimplementasian dari proses casting dalam hal ini adalah investment casting dalam upaya memproduksi komponen towing beam pada konstruksi kapal tunda. Sehingga kedepan diharapkan dapat diproduksi secara khusus dan memiliki standart untuk dipakai di seluruh indonesia terutama kapal dengan bendera klasifikasi Biro Klasifikasi Indonesia. Serta menunjang industri manufaktur baik pada pengusaha galangan kapal atau pemilik kapal tunda di Indonesia serta memberikan peluang pangsa pasar bagi produsen percetakan khusus towing beam. Adapun hasil perhitungan dapat dilihat pada Tabel 1.

Tabel 1. Perhitungan Tegangan Maksimum dengan metode elemen hingga

\begin{tabular}{ccccc}
\hline Panjang kapal $(\mathrm{m})$ & Diameter $(\mathrm{mm})$ & Daerah kontak (sisi ) & \multicolumn{2}{c}{ Stress Max $\left(\mathrm{N} / \mathrm{mm}^{2}\right)$} \\
\cline { 3 - 5 } & & & $\begin{array}{c}\text { Daerah pengamatan } \\
\text { dalam }\end{array}$ & Daerah pengamatan luar \\
\hline$<25$ & 101,6 & 2 & 143,34 & 180,12 \\
$25-35$ & 127 & 2 & 120,85 & 162,93 \\
$35-45$ & 139,7 & 2 & 108,11 & 122,21 \\
$45<$ & 152,4 & 2 & 92,28 & 107,48 \\
\hline
\end{tabular}

Dapat diketahui bahwa setiap kapal tunda memiliki ukuran diameter towing beam yang berbeda pula hal tersebut dapat dijadian sebagai peluang dalam produksi casting khusus bagian ini. Dari hasil perhitungan didapatkan nilai tegangan maksimum yang berbeda- beda berdasarkan ukuran dan geometri dari konstruksi towing beam yang mengalami kontak. Seperti pada ukuran kapal tugboat dengan panjang dibawah 25 meter dengan diameter towing beam 101,6 mm maka mendapatkan nilai tegangan maksimum paling besar yaitu pada daerah pengamatan dalam 143,34 $\mathrm{N} / \mathrm{mm}^{2}$, pada daerah pengamatan luar $180,12 \mathrm{~N} / \mathrm{mm}^{2}$. Untuk tengan paling kecil terdapat pada ukuran kapal tugboat dengan panjang diatas 45 meter dengan diameter towing beam $152.4 \mathrm{~mm}$ yaitu pada daerah pengamatan dalam 92,28 $\mathrm{N} / \mathrm{mm}^{2}$, pada daerah pengamatan luar $107,48 \mathrm{~N} / \mathrm{mm}^{2}$.

Disisi lain semakin baik pelayanan dari sebuah kapal tunda memberikan tuntunan kepada kapal besar maka semakain banyak kemungkinan meningkatkan perekonomian pada daerah tersebut. Studi sebelumnya mengenai perbandingan waktu dan biaya yang diperlukan dalam proses investment casting ini [19] menyatakan ada perbedaan waktu produksi antara cara konvensional dengan cara modern yaitu dari segi waktu selisih hingga 5 minggu , untuk segi harga perlengkapan dan perawatan mengalami perbedaan selisih hingga 40\%, dan untuk total cost secara keseluruhan menjadi tinggi karena adanya biaya casting namun jika dilakukan dalam produksi masal biaya ini cenderung lebih efektif, karena biaya fabrikasi dapat ditukarmenjadi biaya pemasangan / install. Hal itu senada dengan hasil penelitan ini dengan penerapannya di lapangan, lihat Gambar 6, menunjukan hasil sebagai berikut lihat Tabel 2.

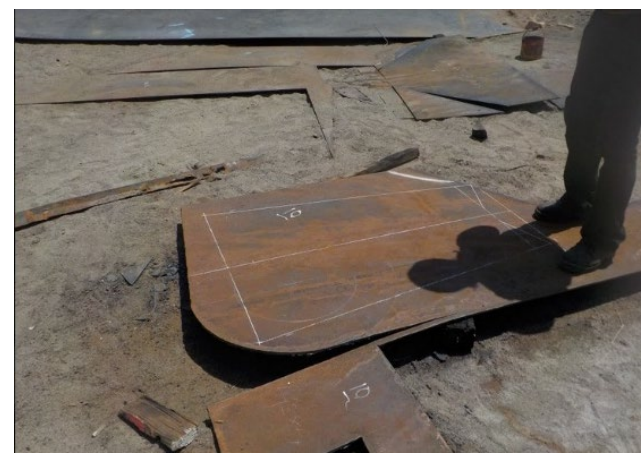

Gambar 6. Proses marking fabrikasi towing beam 
Tabel 2. Perbandingan estiamsi waktu dan cost reparasi towing beam

\begin{tabular}{lcccc}
\hline \multirow{2}{*}{ Pekerjaan } & \multicolumn{2}{c}{ Dengan Proses Fabrikasi } & \multicolumn{2}{c}{ Dengan Pembelian Produk Casting } \\
\cline { 2 - 5 } & Waktu (jam) & Biaya jasa (Rp) & Waktu (jam) & Biaya jasa (Rp) \\
\hline Marking Plat & 2 & 75.000 & - & - \\
Cutting & 5 & 150.000 & - & - \\
Fit up & 4 & 75.000 & - & - \\
Welding & 4 & 600.000 & 3 & 350.000 \\
Product check and repair & 3 & 350.000 & 8 & 600.000 \\
Install & 8 & 600.000 & 3 & 350.000 \\
QC check & 3 & 350.000 & 14 & 1.300 .000 \\
\hline Total & 29 & 2.200 .000 & & - \\
\hline
\end{tabular}

Dapat diketahui jika proses fabrikasi memerlukan waktu yang lebih lama dibandingkan dengan pembelian produk casting yang telah jadi, mampu mengurangi waktu untuk proses reparasi sebesar $52 \%$ atau selisih estimasi waktu 15 jam setara dengan 2,5 hari kerja. Sedangkan dari sisi cost dapat mereduksi biaya estimasi jasa reparasi sebesar $41 \%$ atau selisih Rp. 900.000,-.

Adapun hal-hal yang perlu diperhatikan dalam produksi dengan sistem investment casting adalah :

- Konsep desain dari model lilin yang akan digunakan, ketebalan komponen, kriteria jalur penuangan logam cair untuk pengecoran ( tiap seksi - seksi nya), ukuran sudut yang terbentuk, lubang untuk jalur keluarnya udara agar tidak terjadi porositas atau adanya partikel yang terjebak didalam proses pengecoran.

- Konsep penggunaan material yang digunakan, meliputi temperatur injeksi ketika logam cair yang akan dijadikan bahan pengecoran.

- Konsep penuangan, meliputi waktu yang diperlukan untuk proses penuangan, laju aliran penuangannya.

Hal ini senada dengan studi sebelumnya [20] dimana menurutnya terdapat tambahan faktor akurasi dimensi, jenis densitas materialnya, lapisan ketebalan dari cetakan, serta model support untuk menahan selama proses pengecoran. Selain itu sebagai pertimbangan dalam pemilihan metode casting ini, ada kemungkinan munculnya cacat yang terjadi. Jika dilihat dari faktorya maka terdapat beberapa penyebab terjadinya cacat dalam investment casting ini diantaranya:

- Berdasarkan identifikasi model, meliputi bentuk model atau geometri masternya, jenis material modelnya, jika bentuk model kurang akurat maka hasil cetakannya juga terdapat cacat.

- Berdasarkan teknik atau prosesnya, meliputi cara penuangannya, cara pembersihannya setelah barang jadi, jika proses ini dilakukan secara sembarangan maka tidak menutup kemungkinan akan dapat terjadi cacat pada sisi dalam dan permukaan benda jadi.

- Berdasarkan waktu pendingingannya, meliputi kemungkinan terjadi penyusutan, missrun, coldshut, jika waktu perubahan temperatur ini tidak diperhitungkan maka dapat mempengarui kualitas bentuk hasil cetakan.

\section{Kesimpulan}

Berdasarkan hasil diatas pembuatan suatu produk dengan metode pengecoran tentunya melihat kegunaan dan biaya produksinya . Jika dikaitkan dengan metode pembuatan serta kemudahan pengaplikasiannya hasil dari produk investment casting ini dapat diaplikasikan pada banyak bidang industri. Towing Beam dengan desain dan ukuran standart kapal yang telah ditetapkan oleh klasifikasi Biro Klasifikasi Indonesia dapat menjadi kontruksi penopang yang kuat ketika menerima beban statis dari tali tambang yang digunakan untuk menarik atau mengatur kapal besar.

Dari hasil analisa tegangan maksimum untuk membuat desain yang optimal dari casting pada daerah pengamatan luar adalah $180,12 \mathrm{~N} / \mathrm{mm}^{2}$ dan pada daerah pengamatan dalam adalah $143,34 \mathrm{~N} / \mathrm{mm}^{2}$. Sedangkan untuk penerapan 
investment casting pada produksi towing beam kapal tunda dapat menjadi peluang usaha baru bagi industri manufaktur karena dapat mempersingkat waktu dengan man power yang sama sebesar 52\% atau selisih estimasi waktu 15 jam setara dengan 2,5 hari kerja. dan memperingan biaya fabrikasi bagi industri galangan kapal sehingga mereduksi biaya reparasi $41 \%$ yaitu mengurangi biaya fabrikasi dan quality repair cost.

\section{Daftar Pustaka}

[1] Ariany, Z., Hendra, A., Febriary, S. Standart Pelayanan Minimal (SPM) Dan Sistem Lasing Pada Kapal Ro-Ro Untuk Keselamatan Transportasi Penyebrangan Laut (Studi Kasus KMP. Legundi). GEMA Teknol. 2018 November; 20 (1): p. 26.

[2] Utomo, B., Khristyson, S. F. Studi Perancangan Propulsi Kapal Peti Kemas 100 Teus. Gema Teknol. 2019 April; 20 (2): p. 46.

[3] Kang, M., Seo, J., Chung, H. Ship Block Assembly Sequence Planning Considering Productivity And Welding Deformation. Int. J. Nav. Archit. Ocean Eng. 2018 Juli; 10 (4): p. 450-457.

[4] Prabowo, A. F. R., Yudo, H., Iqbal, M. Analisa Kekuatan Poros Kemudi Kapal Penampung Ikan Tradisional 200 Gt Kabupaten Batang Dengan Metode Elemen Hingga. J. Tek. Perkapalan. 2016 Juli; 4 (3).

[5] Hudaya, H., Fatra, W., Masnur, D. Pengaruh Cetakan Sillicone Rubber dan Temperatur Tuang Lilin terhadap Kualitas Pola Lilin pada Investment Casting. J. Online Mhs. Fak. Tek. Univ. Riau. 2016 Oktober; 3 (2): p. 1-6.

[6] Yuan, C., Jones, S. Investigation Of Fibre Modified Ceramic Moulds For Investment Casting. J. Eur. Ceram. Soc. 2003 Maret; 23 (3): p. 399-407.

[7] Aguilar, J., Schievenbusch, A., Kättlitz, O. Investment Casting Technology For Production Of Tial Low Pressure Turbine Blades - Process Engineering And Parameter Analysis. Intermetallics. 2011 Juni; 19 (6): p. 757-761.

[8] Wang, J., Sama, S. R., Lynch, P. C., Manogharan, G. Design and Topology Optimization of 3D-Printed Wax Patterns for Rapid Investment Casting. Procedia Manuf. 2019 Januari; 34: p. 683-694.

[9] Groth, S., Frohn, P., Engel, B. Product Planning System For Manufacture-Oriented Modeling Of Freeform Bend Tubes Produced By Three-Roll-Push-Bending. Procedia Manuf. 2019 Januari; 34: p. 10-18.

[10] Jie, Z., Dongqi, Z., Pengwei, W., Gang, W., Feng, L., Penglong,D. Numerical Simulation Research of Investment Casting for TiB2/A356 Aluminum Base Composite. Rare Met. Mater. Eng. 2014 Januari; 43(1): p. 47-51.

[11] Aluminium Investment Casting and Rapid Prototyping for Aerospace Applications. Fundam. Alum. Metall. 2018 Januari: p. $123-158$

[12] Park, S. W. Optimization Of Combustion Chamber Geometry For Stoichiometric Diesel Combustion Using A Micro Genetic Algorithm. Fuel Process. Technol. 2010 November; 91 (11): p. 1742-1752.

[13] Pagone, E., Jolly, M., Salonitis, K. The Development of a Tool to Promote Sustainability in Casting Processes. Procedia CIRP. 2016 Januari; 55: p. 53-58.

[14] Li, D., Campbell, J., Li, Y. Filling System For Investment Cast Ni-Base Turbine Blades. J. Mater. Process. Technol. 2004 Mei; 148 (3): p. 310-316.

[15] Pattnaik, S., Jha, P. K., Karunakar, D. B. A Review of Rapid Prototyping Integrated Investment Casting Processes. Proc. Inst. Mech. Eng. Part L J. Mater. Des. Appl. 2013 April; 228 (4): p. 249-277.

[16] Warren, L., Seal, W. Using Investment Appraisal Models In Strategic Negotiation: The Cultural Political Economy Of Electricity Generation. Accounting, Organ. Soc. 2018 Oktober; 70: p. 16-32.

[17] Kurdi, O. Pemilihan Jenis Pembebanan Statik untuk Analisa Tegangan Heavy Duty Truck Chassis Menggunakan 
Metode Elemen Hingga. ROTASI. 2019 Agustus; 21 (3): p. 181.

[18] Singh, R., Singh, S., Kapoor, P. Investigating The Surface Roughness Of Implant Prepared By Combining Fused Deposition Modeling And Investment Casting. Proc. Inst. Mech. Eng. Part E J. Process Mech. Eng. 2014 November; 230 (5): p. 403-410.

[19] X.J., G. The Lattice Structure Configuration Design For Stereolithography Investment Casting Pattern Using Topology Optimization. Rapid Prototyp. J. 2012 Januari; 18 (5): p. 353-361.

[20] Singh, S., Singh, R. Precision Investment Casting: A State Of Art Review And Future Trends. Proc. Inst. Mech. Eng. Part B J. Eng. Manuf. 2015 Oktober; 230 (12): p. 2143-2164. 